\title{
Fars Edebiyatında Yaşar Kemal Çevirileri
}

\section{Yaşar Kemal in Persian Literature}

\author{
Mina RANJBAR $\dot{I}^{1}$
}

'Sorumlu yazar/Corresponding author: Mina RANJBARi (Dr.),

Istanbul, Türkiye

E-posta: mranjbari85@gmail.com

ORCID: 0000-0001-5943-7985

Başvuru/Submitted: 05.03.2020

Revizyon Talebi/Revision Requested:

01.06.2020

Son Revizyon/Last Revision Received:

19.08.2020

Kabul/Accepted: 20.08 .2020

Atıf/Citation: Ranjbari, Mina. “Fars Edebiyatında

Yaşar Kemal Çevirileri." Şarkiyat Mecmuası -

Journal of Oriental Studies 36 (2020), 89-101.

https://doi.org/10.26650/jos.2020.004

\section{öz}

Bu çalışmada Cumhuriyet dönemi Türk edebiyatının önde gelen yazarlarından Yaşar Kemal'in Farsça çevirileri incelenerek, onun Fars edebiyatındaki konumunun tespit edilmesi amaçlanmıştır. Yaşar Kemal'in birçok kez Nobel Edebiyat Ödülü'ne aday gösterilmesi, İran'daki edebiyat çevreleri tarafından ilgiyle karşılanmış, gazete ve dergilerde bu konuda röportaj ve değerlendirme yazıları yayımlanmıştır. Bu çalışmada Yaşar Kemal'in Farsçaya çevrilen romanları ve hikâyeleri üzerinde durulmuştur ve bu çevirilerden hareketle Yaşar Kemal'in Fars edebiyatındaki yerinin tespit edilmesi amaçlanıyor.

Anahtar kelimeler: Yaşar Kemal, Fars edebiyatı, İnce Memed, Farsça çeviri

\section{ABSTRACT}

This thesis uses the research on Persian translations to establish the place of the novels and stories of Yaşar Kemal, one of the best known Turkish authors in the Republic era, in Persian literature. Yaşar Kemal has been selected as a candidate for the Nobel Prize several times, but he has faced criticism in newspapers and journals in Iran. In this work there has been emphasize on the novels and stories of Yasar Kemal, which have been translated in Persian.

Keywords: Yaşar Kemal, Persian Literature, İnce Memed, Persian translation 


\section{EXTENDED ABSTRACT}

Yaşar Kemal, one of the prominent figures of Turkish literature, has more than forty prints of his books, including Ince Memed, in various countries abroad. His novels and one story book were translated into Persian. Ince Memed, translated by Semin Bahçeban in 1974, was the first novel by Yaşar Kemal to be translated into Persian. Fifteen novels of the author, including Ince Memed, have been translated into Persian until now.

Among the forty-four works published by Yaşar Kemal in Turkish, the novel Ince Memed was translated most. The first translation occurred nineteen years after Ince Memed was published in Turkey in 1955. This translation of Bahçeban was published by Emirkabir in 1978, Neşri Ervend in 1983, and Neşri Morvarid in 1990.

The second and third volumes of Ince Memed were translated by İrec Nobaht in 1987 and 1989 and published by Neşri Ney publishing house. The second edition of the third volume was reprinted in 1990 by the same publisher and translator. The first and second volumes were translated by Hüsrev Mehrzad in 2003 and published by Semir Publishing House in one volume.

The first edition of Ince Memed, which was published nine times by different interpreters and publishers, was published before the Iranian revolution (1978); the other versions and all the other novel translations came after the Iranian revolution.

Many of the translations of Yaşar Kemal's works have been published by Iran's leading, prestigious publishers such as Koknus and Neşri Ney. Many of the books translated before 1990 have poor print quality, but the quality of the books published after 2000 is high. Most of the books do not include a foreword or an introduction by the translator or the publishing house. In the books that include a foreword or an introduction, the books, the life, and the works of Yaşar Kemal are introduced; some of them also include interviews made with Yaşar Kemal. Yaşar Kemal's translators are generally among the leading translators in Iran. 


\section{Giriş}

Türk edebiyatının önemli isimlerinden olan Yaşar Kemal' in İnce Memed ile beraber diğer kitaplarının yurtdışında çeşitli ülkelerde yapılan baskı sayısı kırktan fazladır. Yazarın kitap olarak romanları ve bir adet hikâye kitabı Farsçaya çevrilmiştir. 1974 yılında Semin Bahçeban tarafından çevrilen İnce Memed romanı Yaşar Kemal'in Farsçaya çevrilen ilk romanıdır. İnce Memed ile beraber yazarın toplam on beş romanı Farsçaya çevrilmiştir.

Yaşar Kemal'in Türkçede yayımlanmış kırk dört eseri içinde en fazla İnce Memed romanı çevrilmiştir. İnce Memed romanı Türkiye'de 1955 yılında çıktıktan on dokuz yıl sonra 1974'de Semin Bahçeban tarafindan Farsçaya çevrilmiştir. Semin Bahçeban eserin sadece birinci cildini çevirmiştir. Bahçeban'ın bu çevirisi daha sonra 1978'de Emirkabir, 1983'de Neşr-i Ervend, 1990’ da Neşr-i Morvarid yayınevleri tarafından neşredilmiştir.

İnce Memed'in ikinci ve üçüncü ciltleri İrec Nobaht tarafindan 1987 ve 1989 yıllarında yapılmış ve Neşr-i Ney yayınevi tarafından neşredilmiştir. Üçüncü cildin ikinci baskısı ise aynı yayınevi ve aynı mütercim tarafından 1990 yılında tekrar basılmış. Eserin birinci ve ikinci ciltleri 2003 yılında Hüsrev Mehrzad tarafindan çevrilmiş ve Semir yayınevi tarafından tek cilt halinde yayımlanmıştır.

Toplam dokuz kere farklı mütercim ve farklı yayınevlerinden çıkan İnce Memed romanının ilk baskısı İran devriminden önce (1978) ve diğerleri İran devriminden sonra çıkmışlardır. Farsçaya çevrilen diğer romanların hepsi devrimden sonra çıkmışlardır.

Yaşar Kemal'in eserlerinin çevirisinin birçoğu Koknus ve Neşr-i Ney gibi İran'ın önde gelen, prestijli yayınevlerinden basılmıştır. 1990'dan önce çevrilen kitapların birçoğunun baskı kalitesi düşüktür. 2000'den sonra çıkan kitapların baskı kaliteleri yüksektir. Kitapların çoğuna gerek mütercim gerekse yayınevi tarafından önsöz ve takdim yazılmamıştır. Kitaplarda yer alan önsöz ve takdimlerde ise Yaşar Kemal'in hayatı ve eserleri tanıtılmış, bazılarında da Yaşar Kemal ile yapılan röportajlara yer verilmiştir. Yaşar Kemal'in kitaplarını tercüme edenler genelde İran'in önde gelen çevirmenlerindendir.

\section{Yaşar Kemal'in Eserlerinden Yapılan Çeviriler}

Yaşar Kemal'in Farsçaya kitap olarak çevrilen eserleri romanlarından ve hikâyelerden oluşmaktadır. Yaşar Kemal'in hikâyelerine Farsça antolojilerde de yer verilmiştir. Antolojilerde yer alan iki hikâye dışında müstakil olarak Yaşar Kemal'in üç hikâyesi basılmıştır. Böylece Yaşar Kemal'in toplam beş hikâyesi Farsçaya kazandırılmıştır.

\subsection{Romanlar}

\subsection{1. İnce Memed}

Yaşar Kemal'in Farsçaya çevrilen ilk eseri İnce Memed romanıdır. Tamamı dört cilt olan romanın yalnızca ilk üç cildi tercüme edilmiştir. Çevirilerde, metin olarak Türkçe baskısına bağlı kalınmıştır. Yaşar Kemal'i üne kavuşturan ve okuyucuları arasında en bilinen romanı 
olan Ince Memed (1955) birinci cildinin Türkiye'de yayımlanmasından on dokuz yıl sonra, ilk kez 1974 yılında Farsçaya çevrilmiştir.

İran'ın bedensel engelliler için ilk eğitim okulunu açan Jabbar Baghcheban'ın (Cebbar Bahçeban) oğlu Samin Baghcheban (Semin Bahçeban), Ince Memed'i Türkçe başlığıyla Farsçaya çevirmiştir. Daha çok çocuk müzik besteleyicisi olarak tanınan Dr. Samin Baghcheban (Semin Bahçeban) Aziz Nesin ve Nazım Hikmet’ten de Farsçaya çeviriler yapmıştır. Dr. Samin Bahçeban'ın, Türkiye'nin ünlü şair ve yazarlarını İran kültür topluluğuna tanıtan ilk kişi olduğu bilinmektedir.

Türkçeden başka İngilizceden de Farsçaya çeviriler yapan çevirmen, İnce Memed başlığının altında okuyucunun bilgi edinmesi için parantez içinde "İnce" kelimesinin Farsça anlamlarını ( nâzık, bârik şâhe) vermiştir. ${ }^{1}$

Semin Bahçeban, Ince Memed kitabını on sekiz yıl önce, birinci baskısı üzerinden okuyup tanıdıktan sonra eseri Farsçaya tercüme etmeye karar vermiştir. Böylece eserin iki üç bölümünü tercüme etmiştir. Ancak yaptığı çeviriden çok memnun kalmayan Semin Bahçeban, bu memnuniyetsizliğin sebebini şu şekilde açıklar:

"Bir edebi eser ne kadar şiir gibi vezinli olursa, çeviride bir o kadar kendini kaybeder. Ĕger mutlak şiir olursa, eserin yüzde yüz çevirisi de imkânsız olur. Ince Memed şiir değil; fakat Yaşar Kemal çocukluğunda istediği gibi bir âşık olsaydl, onu kendi sazı ile çalıp kendi sesi ile söylerdi. İnce Memed bir roman da değil, sazsız ve sessiz bir âşı̆̆ın söyledikleridir. "’

\subsection{2. Ânsû-yi Kûhestân (Dağın Öte Yüzü)}

Yaşar Kemal'in üç ciltten meydana gelen Dağın Öte Yüzü romanının ciltleri, Farsçaya ayrı ayrı başlıklarda ve farklı zamanlarda çevrilmiştir.

\subsubsection{1. Ânsû-yi Kûhestân (Ortadirek)}

1984 yılında Yaşar Kemal'in Ortadirek (1960) kitabı Reza Seyyed Hoseini (Rıza Seyid Hüseynî) ve Jalal Khosrov Shahi (Celal Hüsrevşahî) tarafından tercüme edilmiştir. Zaman yayınevi bu kitabın birinci baskısını Ânsĥ-yi Kûhestân (Dağın Öte Yüzü) başlığıyla üç bin adet baskıyla basmıştır. Üç yüz doksan sayfa, on sekiz bölümden oluşan bu kitabın bej renkli kapağında hiçbir görüntü ve yazı yer almamaktadır.

\subsubsection{Zemîn Âhen Est ve Âsemân Mes (Yer Demir Gök Bakır)}

Nansi Festivali'nin birinci ödülünü kazanan bu roman Zülfü Livaneli tarafından Mohammad Amin Seyfiala (Mehmet Emin Seyfiela) tarafından 2008 yılında, kitabın Türkiye'de yayınından kırk beş yıl sonra Diğer Yayınevi'nden Zemîn Âhen Est ve Âsemân Mes başlığıyla çıkartmıştır. Gerçi bu kitap Orta Direk ile birlikte 1989 yılında bir ciltte yayınlanmıştır.

1 Yaşar Kemal, İnce Memed, Çev. Samin Bahçeban, Tehran, Kitab-i Zaman Yayınları,1974, s. 3.

2 A.e. 


\subsubsection{Giyâh-i Bîmerg: Ânsû-yi Kûhestân (ÖImez Otu)}

Reza Seyyed Hoseynî ve Jalal Khosrov Shahi tarafından tercüme edilen bu kitabın başlığı Ansû-yi Kûhestân ve parantez içinde Giyâh-i Bîmerg diye geçiyor. Kitabın ilk sayfasında Üçüncü Cilt: Giyâh-i Bîmerg yazılmaktadır. Negâh yayınları bu kitabı 1988 yılında çıkartmıştır.

\subsubsection{Efsâne-yi Ağrı (Ağrı Dağı Efsanesi)}

İlk kez Farsçaya çevrilen Ăgrı Dağı Efsanesi (1972) Rahim Raiesnia (Rehim Reisniya) tarafından çevrilmiştir. Rehim Reisniya 1985 yılında kitabın asıl Türkçesinden tam on üç yıl sonra bu kitabı Donyâ ( Dünya) Yayınevi’nden çıkarmıştır. Kitabın ikinci baskısı 1985 güzünde dört bin adet baskıyla çıkmıştır. Rehim Reisniya daha sonra Akçasazın A ğaları ve Deniz Küstü kitaplarını da çevirmiştir. İki yüz otuz bir sayfadan oluşan bu çeviri kitap $21 \times 14$ boyutlarındadır. Türkçe baskısında olduğu gibi Ali Taygün'ün yönetmenliğiyle Ağrı Dağı Efsanesi tiyatrosundan bazı resimler verilmektedir. Yüz doksan dördüncü sayfaya kadar devam edip son yazıyor diğer sayfadan itibaren Nuhun Gemisi Ardında başlıklı bir yazıyla diğer konu iki yüz otuz birinci sayfaya kadar devam eder.

A ̆̆rı Dă̆ı Efsanesi kitabının önsözünde tercüman, Yaşar Kemal'in İran'da tanınmış bir yazar olduğunu ve onu üne kavuşturan önemli eseri, Ince Memed romanının Semin Bahçeban tarafından olduğunu işaret eder. Farsçaya çevrilmeden önce yirmi altı dile çevrilen Ince Memed romanı, Avrupa yazarlarının büyük beğenisi kazanmış ve 1973 yılında Yaşar Kemal'in Nobel Ödülü'ne aday olarak seçilmesini sağlamıştır. Yaşar Kemal 1973 Nobel Edebiyat Ödülü’nü sadece bir oy farkla Avusturyalı Patrik Vaytaya kaybetmiştir. 1975 yılında ise ödül verenlerin (jüri) özel ön yargılarından dolayı tekrar ödül almaktan mahrum kalmıştır. Ömer (Zülfü) Livaneli 1975 yılında Politika gazetesinde yayımlamak için Stockholm'dan gönderdiği mektupta, Yaşar Kemal'in, Nobel Edebiyat Ödülü’ne aday olma meselesini yorumlamıştır. Zülfü Livaneli’ye göre; Yaşar Kemal'in Nobel Ödülü'ne aday olma haberlerini senelerdir duyuyoruz. Bazen İsveç Yazarlar Birliği adayları seçiyor, bazen de Nobel adaylarını seçmekte resmi etkinlikleri olmayan birlikler onun eserlerine verilen oyları saymıyorlar. Son iki üç senede Yaşar Kemal'in ismi her zaman Nobel ödülü adaylarında ilk isimlerden sayılır. İsveç’te Avrupa yazarlarının birçoğunu imrendirecek kadar başarılı bir yazar olarak büyük bir pozisyona sahiptir. Yedi sene içinde yedi kitabı İsveç’te yayımlanmıştır. İsveç televizyonu sürekli Yaşar Kemal'den film istemektedir. İsveçliler, bu yılın Nobel ödülünü sadece Yaşar Kemal'in hak ettiğine inandıkları için, ödülün Eugenio Montale’ye verilmesinden hiç memnun değiller.’3

\subsubsection{Eger Mâr Râ Bokoșend Ve Dereht-i Enâr Rû-yi Teppe (Yılanı Öldürseler Ve Hüyükteki Nar Ağacı)}

Reza Seyyed Hoseynî (Rıza Seyid Hüseyni) ve Jalal Khosrov Shahi ( Celal Hüsrevşahi) 1985 yılında Negâh Yayınları'ndan bu iki kitabı bir cilt halinde dört bin adet baskıyla çevirmişlerdir. Aynı yılda, aynı yayınevinden Deniz Küstü kitabını Rehim Reisniya çevirmiştir.

3 Yaşar Kemal, Efsâne-yi Ağrı, Çev. Rahim Raiesnia, Tehran, Donya Yayınları, 1985, s. 10. 
Kitabın önsözünde Reza Seyyed Hoseynî, Jalal Khosrov Shahi’nin Türkiye yolculuğunda büyük bir ihtimal "Yaşar Abinin" (Yaşar Kemal'e hitap ediyor) yanında olduğunu söyleyerek önsözü tek başına yazmak zorunda kaldığını söyler. Reza Seyyed Hoseynî kitabın ilk bölümünü teşkil eden Yılanı Öldürseler romanının Yaşar Kemal'in diğer eserlerinden tamamen farklı olduğunu niteleyip kitabın içinde geçen hayaller ve tasvirler dünyasını başarılı buluyor. İkinci romanda ise ( Hüyükteki Nar Ăgacl) romanının konusuna işaret ederek kitabın tamamen romancılık kurallarına uymasıyla beraber düzenli, ince ve hüzünlü olduğunu söyler.

\subsubsection{Gehr-i Deryâ (Deniz Küstü)}

Rahim Raiesnia( Rehim Reisniya) bu kitabı 1985 yılında Negâh Yayınları'ndan tercüme etmiştir. Beş yüz yedi sayfa ve yirmi beş bölümden oluşan bu kitabın hiç önsözü olmadan direk romana başlamıştır. Kitabın kapak görüntüsü, iki balıktan, birisi ölmüş halde birisi ise canlı şekilde ibarettir.

\subsubsection{Tebl-i Helebî (Teneke)}

Uzun Teneke hikâyesi, Türkiye'de Ince Memed romanının birinci cildinin yayın yılında, yani 1955 'te, yayımlandı. İran'da ise Tebl-i Helebî başlığıyla (Farsçada tenekenin karşılığı) Tofigh Sobhani (Tevfik Subhani) tarafından 1988 yılında yani otuz üç yıl sonra Neşr-i Ney Yayınları'ndan çıkmıştır. Sekseni aşkın hikâyeyi kapsayan Teneke, daha sonra senaryolaştırılmış ve defalarca Türkiye dişında sahnelenmiştir.

\subsubsection{Yusufçuk Yusuf (Akçasazın A ğaları)}

İki ciltten ibaret olan Akçasazın A ğaları (Erbâbhâ-yı Akçesaz), aynı zamanda, aynı konuda birbirinden bağımsız yazılıp iki romandan oluşan bir eser olarak nitelendirilir. Demirciler Çarşısı Cinayeti (1973) ile Yusufçuk Yusuf (1975) olmak üzere iki romandan oluşan eserin, Farsçada sadece “Yusufçuk Yusuf” cildi Donyâ-yi No Yayınları'ndan çıkmıştır.1988 yılında çıkan bu eserin çevirmeni, Rehim Reisniya 2000 yılında kitabın ikinci baskısını üç bin üç yüz adet baskıyla çıkarmıştır.

\subsubsection{Pâdișâh-i Fîlhâ (Filler Sultanı)}

Celal Hüsrevşahî 1991 yılında Pâdişâh-i Fîlhâ (Filler Sultanı) kitabının birinci baskısını dört bin dört yüz adet baskıyla Râd Yayınevi'nden çevirmiştir. Kitabın ilk on dokuz sayfasında, "Filler Sultanı ve Sakallı Topal Karınca" kitabı hakkında Erdal Öz’ün Yaşar Kemal ile yaptığı röportaj bulunmaktadır.

\subsubsection{Perendegân Hem Reftend (Kuşlar da Gitti)}

Bu kitabın ilk çevirisi Tebriz'deki Telaş Yayınevi'nden, Kerim Saderî tarafından yapılmıştır. Kitabın beş bin adet basılan birinci baskısı 1991 yılında yayımlanmıştır. Yüz otuz beş sayfadan 
ve sekiz bölümden oluşan bu çevirinin mavi kapağında uçmakta olan sarı ve turunç renkli kuşlar tasvir edilmiştir. İkinci çeviri ise aynı isimle sadece bir ek farkıyla (Perendegân Nîz Reftend) Mostafa İlkhanizade (Mustafa İlhanizade) tarafından Neşr-i Salis Yayınları'ndan çıkmıştır. 1999 yılında tercüme edilen bu kitap ilk baskısından üç bin üç yüz adet basılmıştır.

\subsubsection{Tenhâyî (Salman)}

Yaşar Kemal'in eşi Thilda Kemal'in İngilizceye çevirdiği Salman, The Solitary kitabı, Majid Nourian (Mecit Nuriyan) tarafından İngilizceden Farsçaya Berg-i Zeytun yayınlarından 1999 yılında çıkmıştır. On bölüm, üç yüz dört sayfadan oluşan bu kitabın ilk baskısı beş bin adet baskı yapmıştır.

\subsubsection{Merd-i Kûhestân (Çakırcalı Efe)}

Yaşar Kemal'in daha önce Kuşlar Da Gitti romanını 1991'de çıkaran, Tahran'da Talaş (Telaş) Yayınları'ndan çıkan bu roman Ali Reza Seifettini (Ali Rıza Seyfettini) tarafından Merd-i Kûhestân (Dağ Adamı) başlığıyla 2000 yılında çevrilmiştir. Bu kitap 274 sayfadan oluşmaktadır. Ali Rıza Seyfettini, Ahmet Altan ve Erdal Öz gibi Türk yazarlardan daha önce Farsçaya çeviriler yapmıştır.

\subsubsection{Köroğlu'nun Meydana Çıkışı (Ü̉ç Anadolu Efsanesi)}

Yaşar Kemal'in Üç Anadolu Efsanesi (1968) eseri, İlk olarak Köroğlu'nun meydana gelişi, ikinci olarak Karacaoğlan ve son olarak Alaca Ceyhan olmak üzere, üç efsaneden ibarettir. Bu kitabın ilk bölümü Köroğlu'nun Meydana Çıkışı Mehrdad Narimani (Mehrdad Nerimanî) tarafından 2001 yılında Yılmaz Kurtlar'ın Azerbaycan Türkçesine çevrilmiş kitabından tercüme edilmiştir.

\subsubsection{Be Men Negâh Kon Berâder (Bütün Hikâyeleri)}

Yaşar Kemal'in Bütün Hikâyeleri (1976) kitabı Be Men Negâh Kon Berâder (Baksana Bana Birader) başlığıyla İran'ın iyi çevirmenlerinden sayılan Asad Behrangî (Esed Behrengi) tarafından 2008 yılında, otuz iki yıl aradan sonra ilk baskısının yapıldığı Ebtekar-i No Yayınevi'nden çıkmıştır. İki yüz elli beş sayfadan oluşan bu kitap Türkçede olduğu gibi yirmi hikâyeden ibarettir.

\subsubsection{Gesse-yi Cezire (Bir Ada Hikâyesi)}

Ghoghnus (Kaknüs) yayınlarından çıkan bu kitabın birinci baskısı 2008 yılında Alirıza Seyfettinî tarafından tercüme edilmiştir. 


\subsubsection{Benger Ferat Hûn Est ( Firat Suyu Kan Akıyor Baksana)}

Alirıza Seyfettinî'nin bu çevirisi 2007 yılında, Ghoghnus (Gognus) Yayınevi’nden bin altı yüz elli adet baskıyla çıkmıştır. Kitap, Türkçede olduğu gibi yedi bölümden ve dört yüz kırk sekiz sayfadan oluşmaktadır. Arka kapakta Türkçesinde olduğu gibi yabancı yazarların Yaşar Kemal hakkında yazdığı yazılar bulunmaktadır.

\subsubsection{2. Âb Horden-i Mûrçe ( Karıncanın Su İçtiği)}

Bir Ada Hikâyesi'nin ikinci cildidir. Fırat Suyu Kan Akıyor Baksana'nın tercümanı Alirıza Seyfettinî bu kitabı da bir sene sonra yani 2008 yılında aynı yayınevinden (Gognus) tercüme etmiştir. Bu kitap yedi yüz yirmi yedi sayfa ve dokuz bölümden oluşmaktadır.

\subsubsection{Hurus khan (Tanyeri Horozları)}

Yaşar Kemal'in Farsçaya en son çevrilen kitabı Bir Ada Hikâyesi üçlüsünden Tanyeri Horozları cildidir. Bir ada hikâyesin daha öncede iki cildini çeviren Alireza Seyfettinî bu romanı 2009 yılında Ghoghnus (Gognus) yayınlarından çıkartııştır.

\subsection{Hikâyeler}

Yaşar Kemal'in romanları dışında bazı kısa hikâyeleri de Farsçaya çevrilmiştir. Bu hikâyeler genelde İran'ın en çok okunan gazetelerinde çıkmıştır. Bazıları ise antolojilerde yer almıştır.

\subsubsection{Gazetelerde Neşredilen Hikâyeler}

\subsubsection{Be Sû-yi Çukurova (Çukurova'ya Doğru)}

Yaşar Kemal'in Be Sû-yi Çukurova (Çukurova'ya Doğru) başlıklı hikâyesi 18 Haziran 1998 tarihinde İran'ın en çok okunan gazetelerinden Ettelaat (İttilaat) gazetesinde çıkmıştır. Bu hikâyenin tercümesini Jafar Soleimanikia (Cafer Süleymanikiya) yapmıştır.

\subsubsection{Gûş Kon Dûst-i Men (Arkadaşım Dinle)}

Jafar Soleimanikia (Cafer Süleymanikiya) tarafından yapılan bu tercüme yine aynı Ettelaat gazetesinin 9 Temmuz 1998 tarihli sayısında çıkmıştır. Bu hikâyeyi tekrar Jafar Soleimanikia, Jame Jam gazetesinde 4 Eylül 2001 tarihinde yayınlamıştır. Gûş̧ Kon Dûst-i Men (Arkadaşım Dinle) hikâyesi 1992 yılında Mohammad Majlesi (Muhammet Meclesi) tarafindan çevrilip dünyanın birkaç ünlü yazarının kısa hikâyeleriyle birlikte bir antoloji kitabı halinde basılmıştır.

\subsubsection{3. Şekârçî (Avcı)}

Bu hikâye, Şekârçî (Avcı) başlığıyla Ettelaat gazetesinde 16 Temmuz 1998 tarihinde Jafar Soleimanikia ( Cafer Süleymanikiya) tarafından çıkmıştır. 


\subsubsection{Antolojilerde ve Kitaplarda Yer Alan Hikâyeleri}

\subsubsection{Dâstânhâ-yi Donyâ-yi Gereftâr (Sorunlu Dünya Hikâyeleri)}

Dr. Mohammad Majlesi (Muhammet Meclisi) on iki yll boyunca Lomond Diplomatik dergisinde Henrish Bol, Graham Green, Manoeel Scorza ve Yaşar Kemal gibi ünlü yazarlara ait yayınlanmış bazı hikâyeleri bir araya toplayıp antoloji kitabı şeklinde çıkartmıştır.

Bu çeviri kitabın birinci bölümünde, ilk otuz bir sayfasında Yaşar Kemal'in Gûş Kon Dûst-i Men (Arkadaşım Dinle) hikâyesi yer almaktadır. Bu kitap Donyâ-yi No Yayınevinden 1992 yılında ve yine aynı yayınevinden Bâzî Bâ Terâne (Şarkılarla Oynamak) başlığıyla 2004 yılında çıkmıştır.

\subsubsection{Köroğlu Der Efsâne ve Târîh (Tarihte Köroğlu Efsanesi)}

Yaşar Kemal' in birkaç kitabını Farsçaya çeviren çevirmen Rehim Reisniya kendi yazdığı, Köroğlu Der Efsâne ve Târîh (Köroğlu Efsane ve Tarihte) adlı kitabının son bölümünde Yaşar Kemal'in Üç Anadolu Efsanesi kitabından Köroğlu'nun Meydana Çıkışı bölümünü tamamen çevirip o bölüme aktarmıştır. Kitabın ikinci baskısı 1989 yılında Tebriz'de, Nîmâ Yayınlarından, üçüncü baskısı ise 2000 yılında Donya Yayınevinden çıkmıştır.

\section{Sonuç}

Yaşar Kemal Türkiye'nin Van ilinin Beygörin kasabasındandır. O, Türkiye, Ortadoğu ve dünyadaki insanların tanıdık yüzü ve Türk yazarlarının en önemli parçalarındandır. Türkçe olarak kaleme alınmış olan güçlü eserleri, onun birçok ödül, madalya ve beğeni almasını sağlamıştır.

Yaşar Kemal'in Farsçaya kitap olarak çevrilen eserleri romanlarından ve hikâyelerden oluşmaktadır. Yaşar Kemal'in hikâyelerine Farsça antolojilerde de yer verilmiştir. Antolojilerde yer alan iki hikâye dışında müstakil olarak Yaşar Kemal'in üç hikâyesi basılmıştır. Bu hikâyeler genelde İran'ın en çok okunan gazetelerinde çıkmıştır. Yaşar Kemal'in Farsçaya çevrilen ilk eseri Ince Memed romanıdır. Tamamı dört cilt olan romanın yalnızca ilk üç cildi tercüme edilmiştir. Çevirilerde, metin olarak Türkçe baskısına bağlı kalınmıştır. Ayrıca yazarın Avrupa'da yayımlanan gazete ve dergilere verdiği röportajların bir kısmı da Farsçaya tercüme edilmiş, bunlar çeşitli basın yayın organlarında yayımlanmıştır.Yaşar Kemal, günümüzde hâlâ İan edebiyat çevrelerinde üzerinde tartışılan ve popülerliğini koruyan bir isimdir. Ayrıca onun hakkında değerlendirmeler de bulunmaktadır.Yaşar Kemal hakkında değerlendirmelerde ilk olarak, 1999 yılında Adel Jahanaray (Adil Cehanaray) ve Amin Fakhrara (Emin Fehrara)'nın yayımladıkları yazı yer almaktadır. İran'ın ünlü gazetelerinden olan Abrâr (Ebrar) gazetesinde çıkan bu yazı Şadi-i Ademî Ve Tehsin-i Cehanî (İnsan Mutluluğu Ve Dünya Tebriki) başlı̆̆ıla Yaşar Kemal'in hayatı ve eserleri hakkında bilgi vermektedir. Bu yazıya göre İnce Memed romanı, Yaşar Kemal'in ilk başarılı eseridir.Yazının başka bir yerinde Yaşar Kemal'in dünya bakışının, yeni ve gerçekçi bir bakış açısı olduğu söylenir. Ayrıca Yaşar Kemal'in açık ve sert eleştirileri ve görüşlerinden dolayı hapse düşmesinden ve hapiste kalmasıyla beraber düşüncelerinin değişmesine değinmiştir. $\mathrm{Bu}$ makalede Yaşar Kemal hakkında şöyle bir değerlendirme bulunmaktadır: 


\begin{abstract}
"Yaşar Kemal' in yazılarının derin bir ufka sahip olması ve gerçeklere dayalı olması nedeniyle okuyucu sayısı çok fazladır. Gerçeklere dayalı olma anlayışı ise haberci kökeninden kaynaklanmaktadır. Hatta Yaşar Kemal haberleri dolayısıyla 1955 yılında "Gazete Yazarları Birliği”" ödülünü kazanmıştır. Yaşar Kemal 'in romanlarının genelde rapor tarzında yazıldiğını görmekteyiz. Mesela Akçasazın Ağaları gerçekçi bir görüş̧ çerçevesine sahip olan bir yazı olarak aslında feodalizm sisteminin yatırımcllı sistemine dönüşmesini gösteren bir erbap kul raporudur." ${ }^{4}$
\end{abstract}

Yazının başka bir bölümünde Akçasazın A ğaları romanının dünyanın en ünlü romanlarından birisi olduğuna değinilmiş ve Yaşar Kemal'in Görüşleri başlığıyla ikinci konuya girilmiştir. Bu başlık altında ise Yaşar Kemal'in günümüzde sadece Türkiye'ye ait bir yazar olmadığını, Türkiye'nin sınırlarını aşıp bir dünya yazarı haline geldiği söyleniyor. Onu dünya yazarı yapan en büyük etken sahip olduğu gerçekçi üslubudur. ${ }^{5}$

Yaşar Kemal'in dilinin bazı eserlerinde hayali ve şiirsel olmasına rağmen birçoğunda açık ve gerçek olmasına işaret edilmiş, kendi halkının acılarını, kederlerini ve dertlerini yazılarında yansıtan yazarın, artık kendine ait olmadığını, bu acıları çeken milletine ait olduğu belirtilmiştir. Yazıya göre, kendi milletini seven ve diğer milletleri kardeş bilip halkının derdi ve kederine çare bulabilmek için onlardan yardım isteyen insan (yazar), gerçekte diğer toplumlarda sevilen bir insan olarak tanınacaktır. ${ }^{6}$

Rûzegâr-i Vesl dergisinin otuz dokuzuncu sayfasında, Ağustos 2009 sayısında Alireza Seyfettinî Nevisende-yi Ke Tenhâ Bâ Çeşm-i Çep Mibined (Bir Tek Sol Gözüyle Gören) başlıklı bir yazıda Yaşar Kemal'in kendi hakkında görüşlerini ele almıştır. Alireza Seyfettinî’ye göre Yaşar Kemal sebatkârlığın anlamı olmayan bir ülke insanlarının, trajik kaderinin yazarıdır. Onun eserleri bir ayna gibi, böyle bir dünyada yer alan sebatsızlık, perişanlık ve karışıklığı yansıtmaktadır. Yaşar Kemal, halkının sözlü ve yazılı edebiyatına dayanarak ayrılıklar ve nedenleri ile savaşır. O toplumun yıkıcı ve uğursuz zıtlıklar ile kargaşalıklarından kurtulabilecek yolu, halkın folklora yönelmeleri ve onu dikkate almaları düşüncesindedir?

Ekim 2008 tarihinde Sarmaie gazetesinde çıkan bir habere göre 16 Aralık 2008 tarihinde, İstanbul'da, Abdullah Gül, Türkiye'nin en önemli edebiyat ödülü olan Cumhurbaşkanlığı Kültür ve Sanat Ödülünü edebiyat alanında Yaşar Kemal'e vermiştir. Hadi Soufizade'nin yazısına göre Yaşar Kemal'in böyle bir beyanatta bulunabilecek tek kişi olduğunu söylemek mümkündür. ${ }^{8}$

İran eleştirmenlerinden olan Elham Yekta Temmuz 2007'de Yaşar Kemal'in Firat Suyu Kan Akıyor Baksana romanı hakkında yazdığı yazıda Yaşar Kemal'i İran'daki yazarlarla karşılaştırıp sonuçlara varıyor. Ona göre Yaşar Kemal yazdığ 1 romanlarda, gerçeğin portresini çizmeyi ve gerçekçi izlenim yaratmayı amaçlamıştır. Yaşar Kemal' in gerçekçi düşünce anlayışını yansıtan eserlerinden biri de, Fırat Suyu Kan Akıyor Baksana adlı romanıdır. Ona göre Yaşar Kemal, eserdeki insanı ve olayın gerçekleştiği çevrenin doğasını kendine özgü üslubuyla, mükemmel

4 Adel Jahanara, "Şadi-yi Ademi Ve Tehsin-i Cehani”, Abrar. Nisan 11, 1999, s.7.

5 Adel Jahanara, A.y.

6 Adel Jahanara, A.y.

7 Alireza Seyfettini, "Nevisande-yi Ke Tanhâ Bâ Çeşm-i Çep Mibined”, Rozgare Vasl. Ağustos, 1997. s. 39.

8 Alireza Seyfettini, A.y. 
bir şekilde anlatırken, savaşın toplumsal etkilerine de değinir. Yazıda Yaşar Kemal'in, düz bir zaman çizgisiyle, Fırat Suyu Kan Akıyor Baksana romanının ilk iki bölümünü ele alıp, bilinen gerçekçi usulüyle romanı ilerletebileceği eleştirisi yapılmıştır. Yazıda, genelde bazı İran eleştirmenlerinin kafasında oluşan soru işaretlerine yer verilmiştir. Bunlar ise;

1. Yaşar Kemal, nasıl Yaşar Kemal oldu?

2. Nobel Ödülü adayı olarak, neden Yaşar Kemal seçildi?

3. Orhan Pamuk bile Nobel Ödülü'nü kazanmadan önce, Türkler edebiyatının evrenselleştiğinin sebebi ne idi?" Şeklinde sıralanabilir.9

İran eleştirmenlerinden sayılan Elham Yekta, Şikesti Dubareye Men Ez Yaşar Kemal (Yaşar Kemal'e Tekrar Yenildim) adlı yazısında, Fırat Suyu Kan Akıyor Baksana romanından yukarıda verilen örnekle ilgili duygu ve düşüncelerini; Yaşar Kemal'in uzun uzadıya izah gücünün kendisi gibi profesyonel bir okura azap çektirdiğini, fakat aynı metnin ulaşılmaz, hayali şarkın hayranı ve kolaylık yanlısı olan batılı okur için son derece enteresan ve çekici olduğunu belirterek ifade etmeye başlar.

Yazara göre, Yaşar Kemal'in Fırat Suyu Kan Aklyor Baksana romanı, baştan sonuna kadar kartpostalsı tasvirlerle doludur. Yaşar Kemal bu romanında, Yunanistanlıların tarafını tutmuştur. Aslında Yaşar Kemal, Fırat Suyu Kan Akıyor Baksana romanında eleştirel ve karşıt düşünce açısından ülkesinin tarihini yazmaya çalışmıştır. Bu yüzden de, batılının ona karşı duyduğu aşırı hayranlık ve hatta duyduğu borç hissi doğaldır. Bunun sonucunda, eski ve ilginç bir tarihe sahip olup tarih boyunca batı ve doğunun sınırı olarak tanınan bir ülkeden gelen kartpostalsı yazar Yaşar Kemal, yavaş yavaş medyalarda ve daha sonra da batılıların ağzında tanınmaya başlar ve böylece eseri kendine özgü hiç bir edebi değeri olmadan Nobel Ödülü adayı olur. ${ }^{10}$

Yaşar Kemal'in edebi değer açısından Nobel'i hak etmediğini belirttikten sonra Yaşar Kemal'in neden sadece aday olarak kaldığını, Nobel Ödülü'nün de kendine has kuralları olması ve kolay kolay değerini düşürememesi sebepleriyle açıklar. Yazara göre, Yaşar Kemal'in birkaç sene Nobel Ödülü adayı olarak tüm dünyada isminin geçmesi, kendisinin ve Türkiye'nin isminin dünya çapında duyulup tanınmasını sağladığı için yeterlidir. Elham Yekta, Yaşar Kemal' in Haristan ve Fırat Suyu Kan Akıyor Baksana romanlarını İran edebiyatının tanınmış romancılarından sayılan Abbas Marufi'nin Senfuni-yi Murdigan (Ölülerin Senfunisi) ve Salhayı Belva (Felaket Yılları) adlı romanları ile karşılaştırarak, Marufi eserlerinin edebi değer açısından, Yaşar Kemal eserinden daha iyi ve yüksek bir seviyede olduğunu söylemektedir. ${ }^{11}$

9 Elham Yekta, "Şekest-i Dobareye Men Ez Yaşar Kemal”http://www.ayneha.ir/shownaqd. Temmuz, 2007.

10 Elham Yekta, A.y.

11 Elham Yekta, A.y. 
Hakem Değerlendirmesi: Dış bağımsız.

Çıkar Çatışması: Yazar çıkar çatışması bildirmemiştir.

Finansal Destek: Yazar bu çalışma için finansal destek almadığını beyan etmiştir.

Peer-review: Externally peer-reviewed.

Conflict of Interest: The author has no conflict of interest to declare.

Grant Support: The author declared that this study has received no financial support.

\section{Kaynakça/References}

Kemal, Yaşar (2008), Âb Horden-i Mûrçe, (Çev.) Alireza Seyfettinî, Tehran: Ghoghnus Yayınları.

Kemal, Yaşar (1984), Ânsû-yi Kûhestân, (Çev.) Reza Seyyed Hoseini, Jalal Khosrov Shahi, Tehran: Zaman Yayınlar1.

Kemal, Yaşar (1988), Ânsû-yi Kûhestân (Giyahe Bimerg), (Çev.) Reza Seyyed Hoseinî, Jalal Khosrov Shahi, Tehran: Negâh Yayınları.

Kemal, Yaşar (2008), Be Men Negâh Kon Berâder, (Çev.) Asad Behrangî, Tehran: Ebtekar-i No Yayınları.

Kemal, Yaşar (2001), Bedreghe, (Çev.) Sarvnaz Bigdeli Khamse, Tehran: Meşg-i Emrûz Yayınları.

Kemal, Yaşar(1989), Begzar Haristan Besuzed, (Çev.) İraj Nobakht, Tehran: Neşr-i Ney Yayınları.

Kemal, Yaşar (2007), Benger Ferat Hun Est, (Çev.) Alireza Seyfetinî, Tehran: Ghoghnus Yayınları.

Kemal, Yaşar (1985), Efsaney-i Ağrı, (Çev.) Rahim Raiesnia, Tehran: Donya Yayınları.

Kemal, Yaşar (1990), Efsâne-yi Çiya-yi Ağrı, (Çev.) Teyfour Kordi, Tehran: Neşr-i Rûz Yayınları.

Kemal, Yaşar (1985), Eger Mâr Râ Bokoşend Ve Dereht-i Enâr Rûy-i Teppe,( Çev.) Reza Seyyed Hoseini, Jalal Khosrov Shahi, Tehran: Negâh Yayınları.

Kemal, Yaşar (1988), Erbâbhâ-yi Akçasaz, (Çev.) Rahim Raiesnia, Tehran: Donya-yi No Yayınları.

Kemal, Yaşar (1985), Gehr-i Derya, (Çev.) Rahim Raiesnia, Tehran: Negâh Yayınları.

Kemal, Yaşar( 1974), İnce Memed, (Çev.) Samin Bahçeban, Tehran: Kitâb-i Zaman Yayınları.

Kemal, Yaşar (1978), İnce Memed,( Çev.) Samin Bahçeban, Tehran: Emirkebir Yayınları.

Kemal, Yaşar (1983), İnce Memed,( Çev.) Samin Bahçeban, Tehran, Ebtekat Yayınları.

Kemal, Yaşar (1983), İnce Memed,( Çev.)Amir Esmaieli, Tehran: Neşr-i Ervend Yayınları.

Kemal, Yaşar (1990), İnce Memed,( Çev.) Amir Esmaieli, Tehran: Morvarid Yayınları.

Kemal, Yaşar (2003), İnce Memed,( Çev.) Khosrov Mehrzad, Tehran: Semir Yayınları.

Kemal, Yaşar (2001), Köroğlu'nun Meydana Çıkışı,( Çev.), Mehrdad Narimani, Tabriz: AkhtarYayınları.

Kemal, Yaşar (2000), Merd-i Kûhestân,( Çev.) Alireza Seyfettinî, Tabriz: Talaş Yayınları.

Kemal, Yaşar (1991), Oghab-i Kûhestân,( Çev.) Rahim Raiesnia, Tabriz: Nima Yayınları.

Kemal, Yaşar (1991), Pâdişâh-i Fîlhâ,( Çev.) Jalal Khosrov Shahi, Tehran: Rad Yayınları.

Kemal, Yaşar (1999), Pâdişâh-i Fîlhâ,( Çev.) Jalal Khosrov Shahi, Tehran: Avaze Yayınları.

Kemal, Yaşar (1991), Perendegân Hem Reftend,( Çev.) Karim Saderi, Tabriz: Talaş Yayınları.

Kemal, Yaşar (1999), Perendegân Hem Reftend,( Çev.) Mostafa İlhanizade, Tehran: Neşr-i Salis Yayınları.

Kemal, Yaşar (1987), Şahini Anavarza,( Çev.) İraj Nobakht, Tehran: Neşr-i Ney Yayınları.

Kemal, Yaşar (1988), Tebl-i Helebi,( Çev.) Tofigh Sobhani, Tehran: Neşr-i Ney Yayınları. 
Kemal, Yaşar (2008), Zemin Ahen Est Ve Aseman Mes,( Çev.) Mohammad Amin Seyfiala, Tehran: Başka Yayınlar1.

Jahanara, Adel "Şâdi-yi Ademi Ve Tehsin-i Cehanî”, Abrar. Nisan 11, 1999.

Seyfettini, Alireza “Nevisandeyi Ke Tanha Ba Çeşm-i Çep Mibined”, Rozgare Vasl. Ağustos, 1997.

Yekta, Elham "Şekest-i Dobareye Men Ez Yaşar Kemal”http://www.ayneha.ir/shownaqd. Temmuz, 2007. 
